\title{
SYNTACTIC FEATURES IN MORPHOLOGY: GENERAL PROBLEMS OF SO-CALLED PRONOMINAL INFLECTION IN GERMAN
}

\section{INTRODUCTION}

1.1. Historical Background. - Morphological analysis of inflectional categories has been for a long time a favored field of classical structuralism. American scholars, in this respect, concentrated on the representation of inflected forms in terms of concatenated morphemes. In that framework a form as [ménərn] "to men" would be analyzed as

$$
\text { man }+ \text { masculine }+ \text { plural }+ \text { dative }
$$

where each morpheme represents a class of allomorphs from which the proper member must be chosen according to highly idiosyncratic rules. ${ }^{1}$ The principles and details of this conception were worked out most carefully by Harris. ${ }^{2}$ The shortcomings of such an approach have been pointed out by Chomsky: ${ }^{3}$ it prevents one from making the most of the linguistically interesting generalizations.

At the same time European structuralists treated the problem in a very different way. Adhering to the traditional concept of inflectional paradigm, they took inflectional categories such as case, number, gender, etc. as more abstract entities. Although these entities were also called morphemes, they must not be understood as classes of allomorphs - i.e. of (possibly empty) phonemic sequences - but rather as values of certain infiectional dimensions to which phonemic representations can be assigned only in sometimes very complicated combinations. These representations then are often syncretisms of different inflectional categories and the question arises whether there are general principles governing syncretism and differentiation. The concepts of markedness vs. unmarkedness and of neutralization - already introduced in phonology - were transferred to morphology in order to formulate such principles. Phonemic, syntactic, and semantic aspects of inflectional categories were investigated

1 Thus / $\mathrm{man} /$ has an allomorph /men/ in the environment plural, plural has the allomorphs/e/, /en/, /er/, and zero according to different noun classes. The complex rules for mutual selection have never been stated explicitly.

2 Z. S. Harris, Methods in Structural Linguistics (Chicago, 1951).

3 N. Chomsky, Aspects of the Theory of Syntax (MIT-Press, 1965), 172-77. 
above all from this point of view by Jakobson and Hjelmslev. ${ }^{4}$ Very revealing insights have been gained, both with respect to particular languages and the general theory of inflectional categories. I will consider some of the results and try to show how they are to be incorporated into a unified description within the framework of generative grammar.

1.2. The Present Framework. - In the first few years of its development generative grammar did not pay much attention to the problems of inflection, and in so far as it did, inflectional categories were treated as morphemes in the sense of American structuralism. The situation changed with the introduction of complex symbols and syntactic features into the theoretical apparatus of generative grammar. In Aspects of the Theory of Syntax Chomsky proposed to handle most of the categories governing inflectional processes as features of complex symbols in final derived phrase markers. ${ }^{5}$ Instead of (1) we could then have an analysis roughly as follows : ${ }^{6}$

$$
\left[\begin{array}{c}
+ \text { Noun } \\
+ \text { Masculine } \\
+ \text { Plural } \\
+ \text { Dative } \\
\text { MAN }
\end{array}\right]
$$

MAN here represents a (redundancy free) matrix of phonemic features, underlying the phonetic form [man] and also the inflected stem of [menor] and [menərn]. A complex symbol such as (2) will then trigger the inflectional rules, which finally produce the desired systematic phonemic representation. We will now consider how such facts as syncretization, neutralization, and differentiation, and the concept of markedness for inflectional categories can be dealt with in a principled way by means of features and inflectional rules.

As to the place of inflectional processes within the grammar, it must be noted that only part of them can be handled by phonological rules. This may be the case, e.g., for the fronting of the vowel in the environment of the feature $[+$ Plural $]$ in such German nouns as /brūder/, /muter/, /fāter/ etc. The majority of inflectional rules adding prefixes and suffixes must precede the application of all phonological rules. This is necessary for several reasons, one of them being the phonological redundancy rules. Although there may be partly different rules applying to stems and affxes (e.g., in German feature combinations are much more restricted for inflections than for stems), all redundancy rules must precede the operation of the ordinary phonological rules mapping the systematic phonemic into phonetic representations. In

* See, e.g., R. Jakobson, "Zur Struktur des russischen Verbums", in : Charisteria G. Mathesio quinquagenario ... (Prague, 1932); "Beitrag zur allgemeinen Kasuslehre", in: TCLP VI, 1936; "Shifters, Verbal Categories, and the Russian Verb", Russian Language Project (Harvard University, 1957); L. Hjelmslev, La Catégorie des Cas I (Aarhus, 1935). For a recent treatment of these problems with particular respect to markedness, see J. H. Greenberg, Language Universals (The Hague, 1967). 5 Aspects, ibid.

- This is only a provisional illustration; [ + Dative] will be replaced later by other case features. 
other words, inflectional rules are essentially part of a component of the grammar which - as Chomsky and Halle have recently proposed ${ }^{7}$ for entirely independent reasons - is to intervene between the operation of the syntactic transformations and the phonological rules, thereby mapping the syntactic surface structure of a sentence onto its systematic phonemic representation. This "readjustment compo" nent", following the syntax and preceding the phonology, then is the natural place for morphological rules which play an important role in particular in highly inflected languages. 8

The morphological rules to be discussed below are closely connected with what has been proposed by Fillmore" under the concept of a "post-transformational minor category (function word) lexicon" as opposed to the "pre-transformational major-category (content word) lexicon" belonging to the base of the grammar. The minor category lexicon selects on the basis of certain syntactic features the proper phonological matrix for such grammatical elements as articles, pronouns, preverbs, etc., just as some of the morphological rules subsequently spell out the phonological matrices for affixes on the basis of certain syntactic and morphological features.

\section{PROPERTIES OF FEATURES}

2.1. Types of Features. - The first point relevant to our problem is the fact that the nonphonological features appearing in the syntactic surface structure may be classified in several ways. A first distinction may be made according to the semantic value of the features. A feature such [ \pm Plural] obviously has a direct bearing on meaning. The same is true for [ \pm Count], [ \pm Human], etc. On the other hand, features such as [ \pm Strong Inflection] have no semantic value at all. Intermediate between these poles are features of gender in German and other languages: for a noun such as /fäter/ the feature [ + Masculine] may be predicted on semantic grounds, but not in the same way for nouns as $/ \mathrm{kern} /$, /hūt/, etc. A second classification is according to the source of the features in the course of derivation. We may distinguish four types:

(3) (a) lexicon inherent features, e.g., gender of nouns

(b) base rule inherent features, e.g., number of nouns

(c) lexicon matching features, e.g., $[ \pm$ Count $],[ \pm$ Human $]$

(d) transformationally introduced features, e.g., case, number of verbs and adjectives, gender of adjectives.

7 Personal communication. One of the reasons which led to this proposal is the need of certain Phrase-structure adjustments in order to get the correct accent patterns of Fifth Strèet vs. Fifth Avenue by general rules.

8 For a somewhat more detailed sketch of the anatomy of a generative grammar with respect to morphology see M. Bierwisch, "Skizze der generativen Phonologie", in: Studia Grammatica, VI (Berlin, 1967).

- C. J. Fillmore, "On the Syntax of Preverbs", unpublished paper. 
Since there are no syntactic relations of subcategorization, selection, or government depending on such categories as gender or person, these features are introduced into a Phrase-marker only by lexical insertion. ${ }^{10}$ On the other hand, it is not characteristic for a noun such as mother, house, etc. to appear in the singular or plural form, this feature specification therefore is introduced by the syntactic rules of the base. ${ }^{11}$ And, with the exception of predicate nouns, it cannot be introduced transformationally, since the number-specification contributes to meaning and therefore belongs to the deep structure. The lexical matching features must be specified both by syntactic rules and in the lexicon, their agreement being the condition for the proper insertion of a lexical entry into a given Phrase-marker. The selectional and contextual subcategorization features and the lexical category features such as [+ Noun], $[+$ Verb], etc. belong to this type. Transformationally introduced features finally are assigned to complex symbols by transformation rules. They may or may not already appear elsewhere in the base Phrase-marker. The gender features for instance are assigned transformationally to adjectives, but are lexicon inherent for nouns, whereas case features certainly do not belong to the deep structure at all, but are introduced by transformations only. ${ }^{12}$ We will call features of type (3) (a) and (c) lexical features and those of type (3) (b) and (d) Phrase-marker inherent features, or for short: grammatical features.

It is important to note that the same features may belong to different types, according to their occurrence in different complex symbols. Thus [+ Masculine] is of type (3) (a) for nouns, but of type (3) (d) for adjectives, determiners and most pronouns. Similarly, [+ Plural] is of type (3) (b) or (3) (c) for nouns, but of type (3) (d) for finite verbs and for predicative nouns, adjectives, and determiners. This must be kept in mind in speaking, for instance of markedness or unmarkedness of such features as [士 Plural], [土 Masculine], etc., as will be seen later.

A third classification of features depends on their function within the derivational process. We distinguish three types:

(4) (a) features occurring only in syntactic rules;

(b) features occurring in syntactic and morphological rules;

(c) features occurring only in morphological rules.

10 There may be, of course, agreement in verbs and adjectives for these features. But this is a transformational relation, not belonging to the deep structure.

11 Exceptions in this respect are nouns occurring only in singular or only in plural, namely mass nouns and pluralia tanta respective!y. In these cases [Plural] belongs to type c).

12 In fact, the situation is somewhat more complicated. In certain cases the appearance of a particular case is determined by lexicon inherent features of deep structure elements. Thus the fact that helfen 'to help' requires its object to be a dative must be marked lexically for this verb as opposed to unterstützen 'to support' with accusative. Similarly the case required for the object of prepositions in German must be marked in their lexical entries. But these markings pertain to verbs, adjectives, and prepositions and specificity case-government, not cases. Another problem in connected with more 'substantial' cases as locative, instrumental, elative etc., which certainly have direct bearing on semantic interpretation and therefore belong to the deep structure, just as corresponding prepositions in languages without these substantial cases. See also note 37. 
We will call features of type (4) (a) and (b) syntactic features, those of type (4) (c) morphological features. That is: we have syntactic features with moxphological effects - such as the case features - but not vice versa. ${ }^{13}$ From this it follows that morphological features may be only of type (3) (a), i.e., lexically inherent. ${ }^{14}$ Purely morphological features specify in particular different classes of inflection with all their phonological consequences, for instance weak and strong verbs, or nouns with or without Umlautplural in German etc. (For examples see references in fn. 14).

2.2. Binary Structure. - It seems reasonable to assume that all syntactic and morphological features are binary, i.e. that they assume one of the values ' + ' or '-'. This assumption of course implies that categories with more than two elements are characterized by more than one feature. Thus case and gender, for instance, require two or more syntactic features in many languages..$^{15}$

The assumption of binary syntactic features is by no means new. Jakobson's work on morphology for instance (see references in fn. 4) is completely based on this requirement. The use of only binary syntactic and morphological features clearly has great theoretical advantages. The basic inventory of syntactic features then can be based on simple and general principles. Moreover, the same formal requirements have already been established for the inventory of classificatory phonological features. Nevertheless, the claim of binarism for syntactic and morphological features must be justified empirically. It is one of the purposes of the present paper to contribute to the evidence already collected in this direction.

Since in Jakobson's work on morphology the binarism of syntactic features is connected with the distinction of marked and unmarked categories, such that always one value of a feature must be marked and the other unmarked, one may ask whether it is possible to choose the features in such a way that one value, say ' + ', can be always identified as marked, while '-' specifies the unmarked feature. In this sense the representation of the singular by [- Plural] and that of the plural by [+ Plura1] is in complete agreement with all empirical evidence. Nevertheless, the fact that this principle is not sufficient in general is already known from phonology. Thus the unmarked value for the feature Tense is ' + ' in stops - and perhaps all obstruents - while it is '-' for vowels and perhaps all nonobstruents. That is, the

13 It may be interesting to compare this classification with that according to the semantic value of features. Both (4) (a) and (b) may - but need not - have semantic interpretation. It is very likely, on the other hand, that pure morphological features never have any semantic interpretation.

14 More precisely, not all morphological features are necessarily part of the lexical entries. They may be partly predicted by redundancy rules. But these rules do not belong to the transformational component. For examples see J. R. Ross, "Der Ablaut bei den deutschen starken Verben"; A. M. Zwicky, "Umlaut and Noun Plurals in German", both in: Studia Grammatica, VI (Berlin, 1967); M. Bierwisch and W. U. Wurzel, "Studien zur deutschen Lautstruktur", Studia Grammatica, VIII (Berlin, 1968).

1s Chomsky, ibid., treats cases by means of a single multivalued feature. But this is meant only by way of example, several 'dimensions' for the characterization of case are foreseen. It will be seen below that the use of a least two case features accomplishes a much more adequate analysis of German inflection. 
environment determines which value of a given feature is the unmarked one. Similar (and more complicated) phenomena can be found in syntax and morphology. Thus for several reasons one may consider neuter as the unmarked gender in German, as opposed to feminine, and that is certainly true for such nouns as Haus 'house', Dach 'roof', for all diminutives, such as Häuschen 'small house', Männchen 'little man' (perhaps even in Mädchen 'girl'), but it cannot be considered unmarked in Weib 'woman'.

2.3. Markedness. - Because of such complications as those mentioned in the last paragraph, Chomsky and Halle developed a theory of markedness ${ }^{16}$ that explicitly distinguishes markedness and unmarkedness of features from the values ' + ' and '--'. They assume, that each phonemic feature for a segment in the phonological matrix of a dictionary entry must be either marked, represented as ' $m$ ', or unmarked, represented as ' $u$ '. If an entry is introduced in the representation of a given sentence, then these $u$ 's and $m$ 's are interpreted as ' + ' or '--' depending on the environment, according to partly universal, partly language specific rules. Thus the feature [Tense] remains unmarked in the dictionary for lax vowels and tense stops, later receiving the value " - ' in the former and ' + ' in the latter case. This principle of marking is connected in a natural way with the simplicity measure for grammars by counting only the $m$ 's and leaving aside all the $u$ 's. In other words: one grammar is higher valued than another, if it needs less $m$ 's in its dictionary. Postal and Lakoff have also applied the principle of marked and unmarked lexical features to problems of syntax, ${ }^{17}$ and it is certainly useful in semantics too.

With respect to the above mentioned problem of gender in German, the theory of markedness would suggest a treatment roughly as follows: nouns as Haus, Dach etc. are unmarked for the gender features in the lexicon, and the unmarked features will later be interpreted as characterizing neuters in presence of the feature [- Animate]. In the same way nouns as Frau 'woman', Tochter 'daughter', and Mutter 'mother', although feminine in gender, remain unmarked for gender-features, these being interpreted as feminine in the presence of the semantic feature [+ Female], while $W e i b$ on the other hand must be marked in the dictionary for gender in such a way that the feature interpretation rules yield the irregular neuter in the presence of $[+$ Female $] .^{18}$

The above considerations lead to certain conclusions relevant to the inflectional categories. First, it is obvious that, as far as marked categories can be represented

16 N. Chomsky and M. Halle, The Sound Pattern of English, to appear. Only a very sketchy outline of some of its principles can be given here. Errors of interpretation of these principles with respect to morphology are mine.

17 See G. Lakoff, On the Nature of Syntactic Irregularity, Report to NSF-16, Harvard University (Cambridge, 1965). Certain ideas of Postal's are reported on there.

is These hints are only by way of illustration. In fact, the situation is much more involved as can be seen from such animate nouns as Katze 'cat', Hund 'dog', where the feminine and the masculine gender respectively behave in a sense as unmarked in representing either the female or male animal, respectively, or the whole species. We cannot go into these details here. 
as those which have feature specification $m$ where the corresponding unmarked categories have $u$, markedness is bound to features of type (3) (a) and (c), i.e. to lexical features. This directly follows from the fact that $m$ and $u$ appear only in the lexicon and cannot be assigned to Phrase-marker inherent or transformationally introduced features, and this in turn corresponds to the fact that in a given sentence each feature appearing - even the unmarked one - must have a definite value, i.e., must be either '十' or '-'.

Second, if the concept of markedness is intended to apply also to grammatical features, for instance to case and number, or to gender in adjectives, then there must be further means to explicate it. This in particular concerns morphological syncretization, as far as it is to be explained in connection with the marked-unmarked distinction.

\section{CATEGORIES OF DECLENSION IN GERMAN}

3.1. The so-called Pronominal Inflection of German. - In order to be more concrete we will consider the declension of the German determiners and attributive adjectives not preceded by an overt determiner. This declension is called pronominal because it is historically connected with that of the third person pronoun. In fact, this is still the case synchronically. ${ }^{19}$ The paradigm is as follows:

\begin{tabular}{|c|c|c|c|c|}
\hline & Masculine & Neuter & Feminine & Masculine/Neuter/Feminine \\
\hline Nominative & dieser & dieses & diese & ,... diese \\
\hline Accusative & diesen. & dieses & diese & diese \\
\hline ative & diesem & diesem & dieser & diesen \\
\hline Genitive & dieses & dieses. & dieser & dieser \\
\hline
\end{tabular}

I have rearranged somewhat the usual order of cases and genders so that the syncretisms show up more systematically. The pattern consists of the stem, in this case the demonstrative determiner $/ \mathrm{diz} /$, and the affixes $/ \mathrm{e} /, / \mathrm{en} / / \mathrm{em} /, / \mathrm{er} /$, and $/ \mathrm{es} /$, distributed according to eight 'syncretism fields'. One could think of another arrangement that further reduces the number of syncretism fields, for instance:

\footnotetext{
18 We consider the inflection of adjectives and determiners because the declension of nouns is highly degenerate and not illustrative for the problems in question. Only the stem formation for singular and plural is of morphological interest. For details see M. Bierwisch and W. U. Wurzel, "Studien zur deutschen Lautstruktur", section 2.
} 
(6)

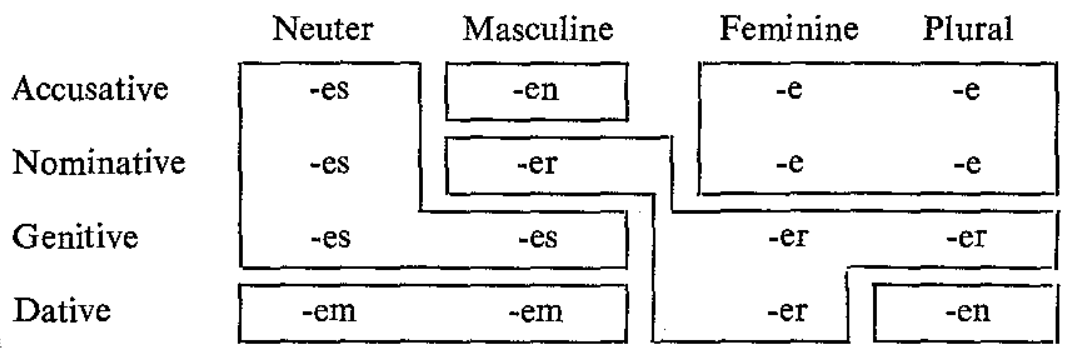

But this would be a suspicious simplification, since (6) does not consist of natural classes. What is meant by this notion will be defined below. Therefore we take (5) as the starting point for further discussion. From that pattern, with certain additional rules, the inflectional forms for all determiners, possessive pronouns, third person personal pronouns and adjectives can be derived. For adjectives there is in addition a so-called weak declension, which shows up after inflected determiners. We return to this problem below.

We will now introduce the features necessary to account for the inflectional pattern (5). These features, of course, must be motivated not only by problems of inflection of adjectives and determiners. But we can hint here only superficially to other evidence for the assumed decisions. ${ }^{20}$

3.2. Case Features. - Since German distinguishes four cases, two binary features suffice. Therefore we will assume a distinction direct vs. oblique, namely, nominative and accusative vs. dative and genitive, and a feature [Governed], separating accusative and dative which are always governed by verbs or prepositions from nominative and genitive, which are not necessarily governed in that sense. ${ }^{21}$. Thus we were led to the feature matrix (7) (a) below. And the inflectional rules could be formulated rather plausibly on this basis. It may be reasonable, however, to introduce a further feature to distinguish the genitive from all other cases and instead of (7) (a) to assume the feature matrix (7) (b):

(7) (a)

Oblique

Governed
Nominative Accusative

$\overline{+}$

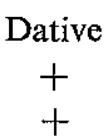

$+$
Genitive

$+$

$-$

20 Certainly syntactic features should finally be taken from a universal set of primitive elements which is part of the general theory of grammar. For the different motivation morphological features see M. Bierwisch, "Skizze der generativen Phonologie", section 6.2.

21 There are apparent counter instances. On the one hand the time accusative as in er schlief den ganzen Tag 'he slept the whole day' seems to be ungoverned. But certainly it must be treated as subordinated to a zero preposition or adverb, which can always be overt: er schlief den ganzen Tag lang. On the other hand, the genitive can be governed by prepositions as wegen 'because of' and verbs as sich erinnern 'remember'. This means then that [+ Governed] is to be interpreted as 'necessarily governed', not 'possibly governed'. Attributive genitive obviously is not governed in the sense in which objects are. In any case, these remarks are only suggestive and not intended to be a theory of case of German. 


$\begin{array}{lcccc}\text { (b) } & \text { Nominative } & \text { Accusative } & \text { Dative } & \text { Genitive } \\ \text { Oblique } & - & - & + & + \\ \text { Governed } & - & + & + & - \\ \text { Genitive } & - & - & - & +\end{array}$

The feature [ + Genitive $]$ may be motivated by at least four reasons. First syntactically, the genitive is to a large extent the result of genitivization under certain transformations in a way in which the introduction of other cases is not possible. Second morphologically, the genitive is the only case for which there is predominantly an overt marking in the singular of non-feminine nouns. Furthermore, the genitive behaves completely differently from all other cases in personal pronouns: ich, mich, mir vs. meiner, du, dich, dir vs. deiner, etc. The third reason may be called lexical: it seems, that $[+$ Genitive $]$ is the main 'syntactic-semantic content' of the preposition von 'of' in its function as genitive suppletion and - together with the features for person marking - of the possessive pronouns. The fourth concerns the universal structure of case systems, where - in Greenberg's formulation - ".there is generally a possessive or genitive case and a case of the subject and one of the object"22 the latter being divided into a direct and a oblique one.

However, the following discussion does not depend much on the choice between the analysis (7) (a) or (b), where the morphological details of personal pronouns are not taken into consideration, and so we are dealing with only two case features. The adoption of (7) (b) - or something similar - will not change our results substantially.

As noted in 2.1., the case features are transformationally introduced and do not belong to the deep structure or to the lexical entries (but see fn. 12). For German this introduction has two essentially different steps: first the case-features of nouns are introduced by nominalization, rules of case government, etc. Later these features, together with those of gender and number, are copied from nouns onto their attributive adjectives and determiners by an agreement transformation. If an analysis of this kind is accepted, where case features never occur in lexical entries, ${ }^{23}$ then the markedness of certain cases cannot be expressed by $m$ for the relevant features. What about the marked-unmarked distinction for cases then? There is syntactic, morphological, and frequency evidence that the oblique cases could be considered as marked as opposed to the direct ones. Within the latter, the accusative is marked as opposed to the nominative. This means that the nominative is completely unmarked, the accusative is marked with respect to government, and the dative is additionally marked with respect to obliqueness. The situation is not so clear for the genitive. It is difficult to say on the basis of morphological criteria such as variation, syncretism, neutralization, whether one of the oblique cases should be considered unmarked as

22 Greenberg, Language Universals, p. 38.

23 More precisely, lexical entries are unspecified, i.e., they have $u$ for the case features, which, interpreted by universal conditions as '-, will explain that - unless additional conditions are imposed - nouns appear in the nominative. The same holds for number, where normally the singular shows up. 
opposed to the other. It seems most reasonable to me to assume that both are marked, but with respect to different features. If this interpretation is the correct one, then (7) (b) would account for it with the interpretation of ' ' + ' as the marked value of a given feature. If, on the other hand, one of the oblique cases should be considered unmarked with respect to the other, in this case the genitive as opposed to dative, then (7) (a), under the same interpretation of ' + ' and ' - ', would account for the markedness of the dative. This interpretation, however, would presuppose a general principle which could be phrased as follows:

(8) The general theory of grammar must provide a set of grammatical features in such a way, that for each particular language, on value, say '-_.', always characterizes the unmarked category.

But such a principle would conflict with one of the most important achievements of Chomsky's and Halle's theory of markedness improving on former treatments of these phenomena, viz. that the feature values ' + ' and '- - cannot invariably be identified as marked or unmarked independently of the environment (cf. the examples given in section 2.3.). Since there is no reason to abandon this achievement for the grammatical features, condition (8) must be rejected. As far as there is evidence for markedness of grammatical features, other means accounting for it must therefore be found. We will discuss this problem in section 8., where under (23) a more reasonable principle than (8) is suggested.

3.3. Gender and Number Features. - The three genders of German require two features. We will assume the following analysis:

$\begin{array}{lccc} & \text { Feminine } & \text { Masculine } & \text { Neuter } \\ \text { Masculine } & - & + & - \\ \text { Feminine } & + & - & -\end{array}$

With respect to markedness, the situation is not very clear for the grammatical gender features. (For the markedness of lexical gender features see the remarks in section 2.3) There is certain evidence that the feminine gender must be marked as opposed to masculine and neuter: feminine always has the fewest case distinctions. This is somewhat in conflict with the fact that in the case of gender neutralization in the plural the forms of the feminine appear with the exception of only the dative. The situation is still more complicated for the relation masculine vs. neuter. The masculine always shows the greatest case differentiation which should be a characteristic of the unmarked gender, while in almost all cases of syntactic and morphological neutralization of gender the neutral form shows up, for instance, in the neutral $E s$ in Es ist gut, daß du gehst 'it is good that you are going'. This suggests that decisions about markedness of genders cannot be motivated on morphological grounds only (cf. the remarks in section 2.3.).

The distinction of singular vs. plural is simply represented by [ - Plural $]$ and $[+$ Plural $]$. Here no difficulties arise: The plural is clearly the marked form according to semantic, syntactic, morphological, and frequency evidence. 
3.4. Types of Inflection. - As noted above, the inflectional pattern (5) applies, with minor modifications, to all determiners, including possessive and demonstrative pronouns, relative and personal pronouns, and to attributive adjectives not preceded by an inflected determiner within the same Noun Phrase. This fact can be accounted for by treating all pronouns syntactically as determiners. This suggestion has recently been made by Postal and further developed by Fillmore. ${ }^{24}$ It is motivated by several independent reasons which are also valid for German and further substantiated by morphological considerations: Since all determiners are marked categorically as [+ Determiner] by early syntactic rules, the affixes displayed in (5) are added only in the environment [ + Determiner]. Exceptions must be made for the personal pronouns of the first and second person which are highly idiosyncratic in several respects. In order to get the strong or pronominal inflection of adjectives which are redundantly marked as [- Determiner] it is then necessary only to change the value of that feature into [+ Determiner] if no inflected determiner procedes in the same Noun Phrase. An adjective belonging to a Noun Phrase then undergoes pronominal inflection, if marked [ + Adjective, + Determiner], and is weakly inflected, if marked [ + Adjective, - Determiner $]$; it is not inflected at all, if not dominated directly by a Noun Phrase.

3.5. Natural Classes of Categories. - The feature treatment of inflectional categories enables us to transfer to morphology the notion of natural class defined by Halle for phonology. ${ }^{25}$ The morphological categories to be considered here are represented by bundles of features of the following sort:

$$
\left[\begin{array}{ll}
\alpha & \text { Adjective } \\
+ & \text { Determiner } \\
\beta & \text { Plural } \\
\gamma & \text { Masculine } \\
\delta & \text { Feminine } \\
\varepsilon & \text { Oblique } \\
\zeta & \text { Governed }
\end{array}\right]
$$

where the Greek letters are variables over ' + ' and ' - ' and $\gamma$ and $\delta$ cannot both be ' + '. If we were to accept the analysis (7) (b) for the German cases, then we would have to add [n Genitive] to (10), with appropriate restrictions on the values for $\varepsilon, \zeta$, and $\mathrm{n}$. We may now refer e.g., to all plural forms, ignoring case and gender, simply by indicating [+ Plural], or to all governed cases of the singular by [ - Plural,

24 P. M. Postal, "On so-called 'Pronouns' in English", to appear in Monograph Series on Language and Linguistics No. 19, Georgetown University Institute of Language and Linguistics (Washington, D.C.); C. J. Fillmore, On the Syntax of Preverbs.

as M. Halle, "On the Bases of Phonology", in: Fodor and Katz eds., The Structure of Language (New Jersey, Englewood Cliffs, 1964). - Recently Halle (personal communication) has somewhat modified the notion of natural classes. Instead of defining a class $C$ as an absolute natural class it is now said to be more natural than some other class $C^{\prime}$, i.e., the absolute notion has been replaced by a relative one. This refinement, however, does not have any bearing on the present discussion. 
+ Governed]. We may then define a natural class of categories as a set of forms which can be characterized by less features than each of its elements or disjunctive subclasses. Thus, for instance, the set of categories that requires the affix /em/is a natural class, represented by (11) (a), which has less features than the full characterization of both masculine or neuter dative singular, while the set of categories with affix /en/, represented by (11) (b), where brackets enclose alternative choices of feature bundles, is not a natural class:

(11) (a)

$$
\left[\begin{array}{l}
+ \text { Determiner } \\
- \text { Plural } \\
- \text { Feminine } \\
+ \text { Oblique } \\
+ \text { Governed }
\end{array}\right]
$$

(b) $\left.\left.\left[\begin{array}{c}+ \text { Determiner } \\ + \text { Governed } \\ + \text { Oblique } \\ + \text { Plural } \\ - \text { Oblique } \\ - \text { Plural } \\ + \text { Masculine }\end{array}\right]\right\}\right]$

Similarly, the set of forms inflected in /es/ is not a natural class, while the subsets nominative/accusative neuter and masculine/neuter genitive are. The same considerations hold for the /er/-inflected forms. Thus it can be seen why pattern (5), but not (6), consists of natural classes. In other words, we are not interested in collapsing all forms with identical affixes, but only those which form natural classes.

\section{RULES FOR PRONOMINAL INFLECTION}

4.1. Some Phonological Remarks. - The phonological shape of the affixes which must be introduced by the inflectional rules can be reduced to $/ \mathrm{m}, \mathrm{n}, \mathrm{r}, \mathrm{s}, \mathrm{e} /$ for independent phonological reasons. The /e/ of affixes ending in a consonant will be introduced later by a very general rule for e-epenthesis. ${ }^{26}$ Furthermore, since /e/ is the only vowel appearing in inflections, and is certainly the least marked vowel for German, and since, moreover, no glides occur in inflections, it will be sufficienć to specify the affix /e/ simply as vocalic and non-consonantal, leaving the specification of all other features to redundancy and markedness interpretation rules. Similarly, since $/ 1 /$ never occurs in inflections, it will be sufficient to mark $/ r /$ as liquid. For $/ \mathrm{m} /$ and $/ \mathrm{n} /$ it is sufficient to specify them as [ + nasal] and to distinguish them as grave and non-grave respectively. And since the unmarked value for gravity with respect to nasal consonants is '-', even this specification may be superfluous for $/ \mathrm{n} / .^{27}$ Similar considerations may show that it is sufficient to characterize /s/as [+ strident], tenseness and non-gravity being left to markedness interpretation and the

26 For details see M. Bierwisch, W. U. Wurzel, "Studien zur deutschen Lautstruktur".

27 This, by the way, explains the great tendency in many dialects of German to substitute the dative affix $/ \mathrm{m} /$ by $/ \mathrm{n} /$ without necessarily losing the accusative-dative distinction. (By no means a purely phonological process is involved, where this distinction disappeared. See below section 8.4.). 
remaining features to redundancy rules. Thus, the five affixes are phonemically represented in their maximally redundancy free form as follows:

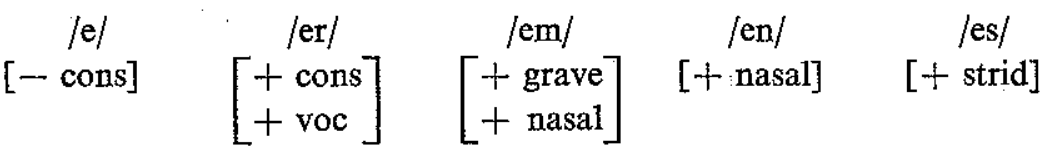

The possibility of this drastic reduction of the phonemic "content" of the inflectional affixes makes it clear that it is more important to classify and introduce the affixes according to the syntactic features involved rather than the phonemic ones.

For the sake of simplicity, however, we will represent the affixes in the rules to be given as /e, r, m, n, s/, these have to be understood as abbreviations for the feature bundles displayed in (12).

4.2. Inflectional Rules. - We are now ready to formulate a set of rules introducing the correct inflections. We will assume for the moment that the case-, number-, and gender-features have been copied by an agreement transformation onto the stems of determiners and attributive adjectives and that the latter have been marked as [+ Determiner] where necessary. The inflection will then consist in the introduction of the affixes immediately after the stem, bearing the relevant syntactic feaţures, and before word boundary. For several phonological reasons it must be assumed that the phonemic matrix representing the stem morpheme and the affix are separated by a morpheme boundary. We will not represent it explicitly in the rules. These then are as follows:

(R 1) Nom. Masc. Sing.

$$
\varnothing \rightarrow \mathrm{r} /\left[\begin{array}{l}
+ \text { Det } \\
- \text { Plur } \\
+ \text { Masc } \\
- \text { Obl } \\
- \text { Gov }
\end{array}\right]-
$$

(R 3) Nom/Acc. Neut. Sing.

$$
\varnothing \rightarrow \mathrm{s} /\left[\begin{array}{l}
+ \text { Det } \\
- \text { Plur } \\
- \text { Masc } \\
- \text { Fem } \\
- \text { Obl }
\end{array}\right]
$$

(R 5) Gen. Masc/Neut. Sing.

$$
\varnothing \rightarrow \text { s } /\left[\begin{array}{l}
- \text { Adj } \\
+ \text { Det } \\
- \text { Plur } \\
- \text { Fem } \\
+ \text { Obl } \\
- \text { Gov }
\end{array}\right]-
$$

(R 2) Acc. Masc. Sing.

$$
\varnothing \rightarrow \mathrm{n} /\left[\begin{array}{c}
+ \text { Det } \\
- \text { Plur } \\
+ \text { Masc } \\
- \text { Obl } \\
+ \text { Gov }
\end{array}\right]-
$$

(R 4) Dat. Masc/Neut. Sing.

$$
\varnothing \rightarrow \mathrm{m} /\left[\begin{array}{c}
+ \text { Det } \\
- \text { Plur } \\
- \text { Fem } \\
+ \text { Obl } \\
+ \text { Gov }
\end{array}\right]-
$$

(R 6) Nom/Acc. Fem. Sing./Plur.

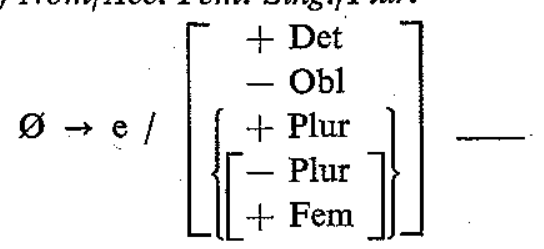


(R 7) Gen/Dat. Fem. Sing./Gen. Plur.

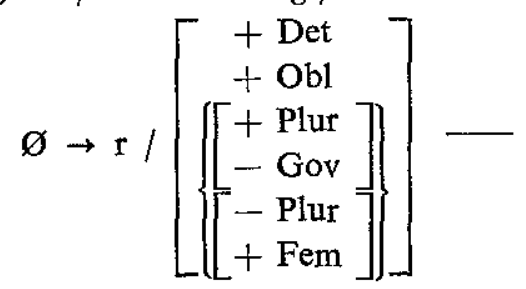

(R 8) Dat. Plur.

$$
\varnothing \rightarrow \mathrm{n} /\left[\begin{array}{c}
+ \text { Det } \\
+ \text { Plur } \\
+ \text { Obl } \\
+ \text { Gov }
\end{array}\right]-
$$

The rules ( $R$ 1) to ( $R$ ) clearly correspond to the eight syncretism fields of pattern (5) above. The indication of [-Adj] in (R 5) is needed because only proper determiners have/er/, while adjectives take the affix /en/ in this case: dünnen Weins, not *dünnes Weins "diluted wine". We will account for these adjective forms in a later reformulation of the rules. Each of these rules must be applied only once to a given complex symbol, because otherwise we would derive such impossible forms as *diesererer etc. This convention is for the time being only an ad hoc stated condition. We will see later that it is deeply connected with basic principles of morphology and grammar in general.

The above rules can be somewhat reduced by certain notational transformations. Thus, if we allow two rules such as (13) (a) to be collapsed to (13) (b):

$$
\begin{aligned}
& \mathrm{A} \rightarrow \mathrm{B} / \mathrm{CX} \quad \mathrm{YD} \\
& \mathrm{A} \rightarrow \mathrm{E} / \mathrm{CZ} \_\mathrm{UD}
\end{aligned}
$$

(b)

$$
\mathrm{A} \rightarrow\left\{\begin{array}{ll}
\mathrm{B} / & \mathrm{X} \_\mathrm{Y} \\
\mathrm{E} / & \mathrm{Z} \_\mathrm{U}
\end{array}\right\} / \mathrm{C} \_\mathrm{D}
$$

then we can also restate with a slightly different convention, for instance, ( $R$ 1) and (R 2) as (R 1'):

(R 1') Nom/Acc. Masc. Sing.

$$
\varnothing \rightarrow\left\{\begin{array}{l}
\mathrm{r} /[-\mathrm{Gov}] \\
\mathrm{n} /[+\mathrm{Gov}]
\end{array}\right\} /\left[\begin{array}{l}
+ \text { Det } \\
- \text { Plur } \\
+ \text { Masc } \\
-\mathrm{Ob} 1
\end{array}\right]-
$$

Notational conventions of this kind are by no means arbitrary. They must be chosen in such a way that they yield a simpler formulation if and only if this simplification expresses a significant generalization. ${ }^{28}$ The principle of double environments, illustrated by (13) (b) and ( $1^{\prime}$ ) is of this type, as is known from other evidence. Of course, ( $R 1^{\prime}$ ) allows no judgment as to the relevance of the sparing of four features. We could further reduce $(R 1)$ to $(R$ ) on the same principle by collapsing

28 For detailed discussion of this problem see N. Chomsky and M. Halle, "Some Controversial Questions in Phonological Theory", in: Journal of Linguistics I, Nr. 2, 1965, and N. Chomsky and M. Halle, The Sound Pattern of English. 
them all to a single rule, extracting the recurrent feature $[+$ Det $]$ from all the environments and stating it as the general environment for the whole collapsed rule. We would save then seven further features. Reducing the collapsed rule as much as possible by means of split environments we come to the following complex rule, which also accounts by subrule e) for the affix /en/ of genitive singular masculine and neuter:

(IR 1') Pronominal Inflection

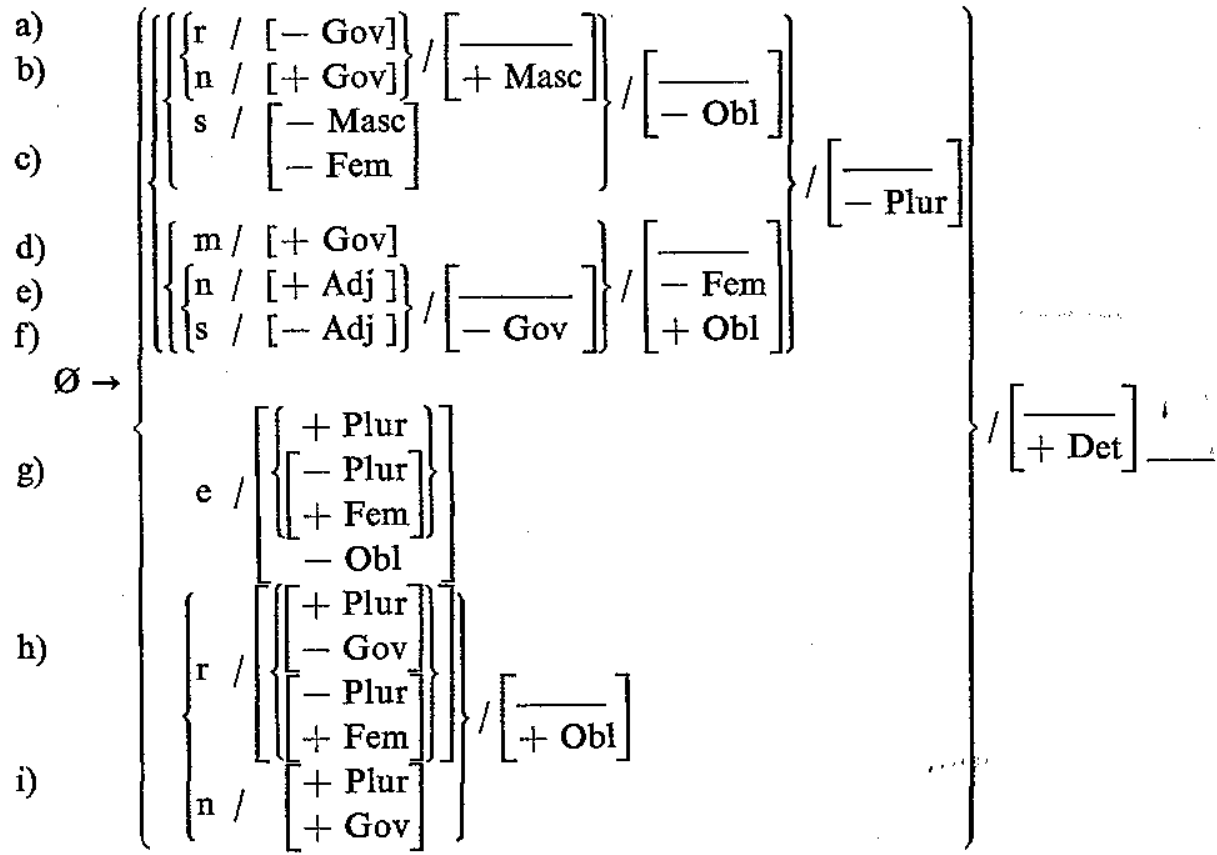

This formulation clearly shows the greater differentiation of inflection within masculine and neuter singular as opposed to feminine and the entire plural: 13 syntactic features are needed for subrules a) through $f$ ) and only 11 for the rest. This corresponds somehow to the principle of greater syncretization within marked categories. Comparing now (R 1) through (R 8) with (IR 1') we see that instead of 49 syntactic features in the former formulation only 26 are needed in (IR 1') which in addition accounts for the inflection of the genitive of adjectives. (We are counting thereby $\varnothing$ as a syntactic feature and we will replace it below by an overt feature. If we were to ignore it, we would have 41 vs. 25 syntactic features. The number of phonological features is 11 and 12 respectively.) This is obviously an important simplification. But even this leaves us with a rather complex set of subrules. One should therefore think of a simplification which is explicitly based on the well-known interplay of markedness and neutralization. 
4.3. Neutralization Rules. - If a certain distinction is suspended in the environment of a given category $C$, then, according to a widely assumed principle, it is either neutralized only for the marked value of $C$ or for both the marked and the unmarked value, but never for the unmarked value alone. ${ }^{29}$ Thus gender is neutralized in the pronominal inflection of German in the environment [ + Plural], the distinction between governed and non-governed cases is neutralized for the direct, but not the oblique cases in the neuter and in the plural, and in the presence of $[+$ Feminine $]$ also for the oblique cases. It is never neutralized for the oblique cases only. By the way, one may ask whether this principle is valid since, as was already pointed out, the syncretism of nominative and accusative in the neuter and their distinction for the masculine would be a counterinstance given that the neuter is the unmarked gender. However, the principle in question states only a condition on neutralization in case there is one. It says nothing about whether and where neutralization really takes place in a given language. This means that morphological neutralization in particular languages cannot be accounted for by universal conventions but must be expressed, if necessary, by particular rules. These rules would be for the pronominal inflection as follows:

$$
\begin{aligned}
& {[+ \text { Plur }]} \\
& {\left[\begin{array}{l}
- \text { Masc } \\
- \text { Obl }
\end{array}\right] \rightarrow\left[\begin{array}{l}
- \text { Masc } \\
- \text { Fem }
\end{array}\right]} \\
& {[+ \text { Fem }] \rightarrow[- \text { Gov }]}
\end{aligned}
$$

These neutralization rules, of course, must precede the inflectional rules and (NR 1) must precede (NR 2) and (NR 3), the ordering of the latter two being immaterial. (NR 1) through (NR 3) is the most economical set of neutralization rules I have been able to find. Let us see now what the incorporation of them into the morphological component of a German grammar would save with respect to the proposed inflectional rules. Since after (NR 1) $[+$ Masc $]$ and $[+$ Fem $]$ never occur in the environment of [+ Plur], the specification of [- Plur] in (R 1), (R 2), (R 6), and (R 7) becomes superfiuous. In the condensed form (IR 1') [- Plur] is abundant only in the subrules g) and $h$ ). However, the saving of four or two features respectively is at the expense of three feature specifications in (NR 1). Therefore it yields no simplification. (NR 2) and (NR 3) do not save any features and are therefore completely worthless.

More important than feature counting, however, is the fact that many of the neutralization phenomena are already handled in a very general and more natural way by the principle of reference to natural classes only and partly by the use of double

29 See, for instance, J. H. Greenberg, Language Universals. A similar principle follows from Hjelmslev's laws of suspension and syncretization, as far as I understand them. See La Catégorie des Cas. Jakobson, in his "Beitrag zur allgemeinen Kasuslehre", is more careful in hinting only at certain asymmetries in inflectional patterns. 
environments. Thus the irrelevance of gender specification for the plural forms is accounted for by referring to the plural only by $[+$ Plural $]$ without mentioning the gender features. By this principle, moreover, we have dispensed with postulating ad hoc that the gender appearing in the plural is the neuter as is stated in (NR 1). This observation, by the way, holds also for other inflectional patterns of German. Instead of using neutralization rules, we have to look for a more adequate way to improve (IR 1').

\section{AGREEMENT RULES}

5.1. Feature Duplication. - Before further discussing the inflectional rules I will outline the rules which have been presupposed until now, namely those accounting for concord in German noun phrases.

As mentioned above case-, number-, and gender-features are partly lexicon-inherent, partly base rule inherent, and partly transformationally introduced (only for nouns). From nouns they must be transferred to determiners and adjectives. This will be accomplished by a rule of the following form:

(T 1) Noun Phrase Agreement

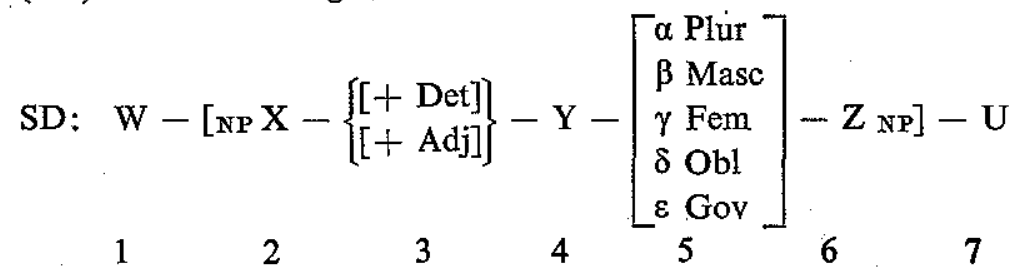

SC: $112\left[\begin{array}{l}3 \\ 5\end{array}\right] \quad 4 \quad 5 \quad 6 r$

By (T 1) the specified features of the fifth element in the structural description, which is the only noun directly dominated by the noun phrase in question, are added to the determiner and to all adjectives belonging to the same NP. The placement of (T 1) among the transformational rules is not a trivial question. (T 1$)$ has to follow on the one hand the rules which introduce case features, including the nominalization rules, and also the relative clause rule and those for the reduction of relative clauses to attributive adjectives. On the other hand in order to get the correctly inflected forms in noun phrases without a noun, it has to precede pronominalization and deletion of lexically empty nouns. That is, (T 1 ) must be part of the transformational cycle. We cannot go into the details here any further.

5.2. Inflected and Uninflected Forms. - As already pointed out adjectives must be inflected only if they are dominated by a node NP in the surface structure. It must be noted that determiners are sometimes not inflected either, or have, as it were, zero inflection. The indefinite article ein, the negative kein and all possessive pronouns 
mein, unser, dein, etc. remain without an affix in the masculine and neuter nominative and neuter accusative. These facts require an indication whether adjectives and determiners have to undergo inflectional rules or not. This can be done by introducing a feature [ + Inflection] under appropriate conditions making it part of the context restrictions in the inflectional rules. The rules providing this feature are somewhat clumsy because of the special environment. (T 2) and (T 3) are the simplest formulation I was able to find. We make use here of Boolean functions of features. The notation $\langle F\rangle\langle G\rangle$ is to be understood as: $F$ and/or $G$ must be present, not necessarily both, but at least one.

(T 2)

$$
[+ \text { Det }] \rightarrow[- \text { Rule }(\mathrm{T} 3)] /\left[\mathrm{NP}\left[\begin{array}{c}
+\overline{+ \text { Indefinite }} \\
+ \text { Negative } \\
+ \text { Possessive }
\end{array}\right]\left[\begin{array}{c}
\mathrm{N} \\
- \text { Plural } \\
- \text { Feminine } \\
- \text { Oblique } \\
\langle- \text { Governed }\rangle \\
\langle- \text { Masculine }\rangle
\end{array}\right] \mathrm{Y}_{\mathrm{NP}}\right]
$$

(T 3) Marking for Inflection

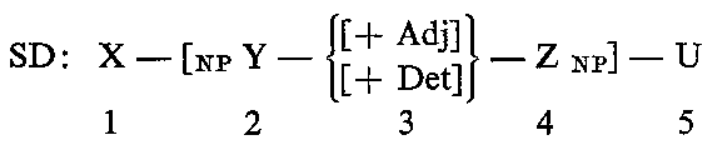

$\mathrm{SG}: 12\left[\begin{array}{c}+ \text { Inflection } \\ 3\end{array}\right] 45$

The purpose of (T 2) is to exclude those determiners which are not to be inflected from the application of (T 3). (T 3 ) then introduces the feature [ + Inflection] for all other cases of determiners and attributive adjectives. The determiner referred to in (T 2) must be followed by a noun or an adjective within the same NP because otherwise all determiners are inflected, as in Keiner sah ihn vs. Kein Mensch sah ihn 'nobody saw him'. The feature [ + Possessive] may be replaced by [ + Genitive] if the analysis (7) (b) for cases is accepted. Notice, by the way, that there are certain non-native adjectives such as rosa 'pink', lila 'violet', etc. which are never inflected and must be marked [- Rule (T 3)] in the lexicon. ${ }^{30}$ The rules (T 2) and (T 3) apply very late in the transformational component, and it may very well be the case, that they do not belong to syntax at all, but are part of the readjustment component, i.e., that they are morphological transformations. But this is a question of minor importance, since nothing syntactically depends on (T 3).

30 For details of the use of rule-features such as [- Rule (T 3)], see G. Lakoff, On the Nature of Syntactic Irregularity. 
5.3. Affix Categorization. - Instead of introducing the feature [+ Inflection] one could add by (T 3) a new formative $[+$ Affix] behind adjectives and determiners. This formative may be considered as a degenerate complex symbol consisting of only one quasi-categorial feature which is later supplied with phonological content by the inflectional rules. In this case the dummy symbol $\varnothing$ in (R 1) through (R 8) must be replaced by [+ Affix]. In order to introduce this formative the structural change of (T 3) has to be replaced by that of (T 3'), where ' $>$ ' designates concatenation:

\section{(T 3') Affixation of Adjectives and Determiners}

SD: the same as in (T 3)

SC: $123 \frown[+$ Affix $] 45$

The application of (T 3') to a subtree like (14) (a) yields (14) (b):

(14) (a)

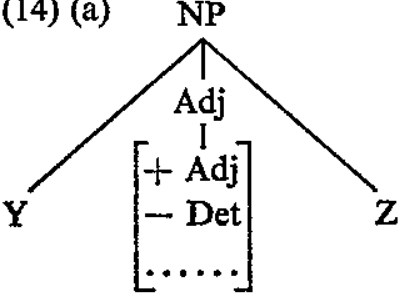

(b)

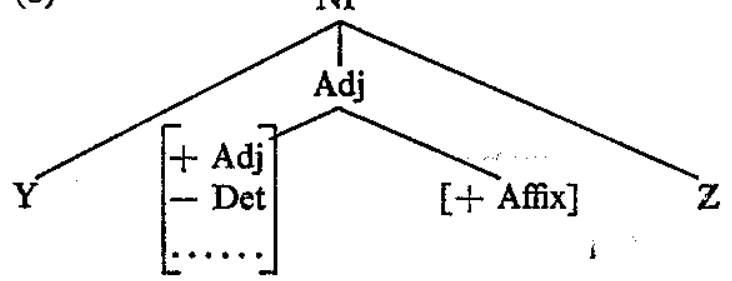

In other words, the affix phonemically specified by later inflection rules becomes a morphological constituent of the lexical element adjective or determiner respectively. It is categorized as affix by the feature introduced in ( $\left.T 3^{\prime}\right)$. There must be in addition a general convention for insertion rules like (T $\left.3^{\prime}\right)$ stating that they must be applied only once to a given constituent in order to prevent the introduction of an indefinite number of new elements, in this case affixes. Such a treatment of affixation could perhaps provide information needed in several phonological rules where reference to the affixal character of certain phonological segments is necessary. It is obvious, however, that this problem must be finally solved in a more general way accounting for the categorization of inflectional and derivational affixes on the basis of uniform and general principles. Nevertheless, (T 3') may indicate the lines along which those principles could be developed. For the time being we will adopt ( $\left.\mathrm{T} 3^{\prime}\right)$ rather than (T 3) and operate with the constituent [+ Affix] instead of $\varnothing$.

5.4. Strong and Weak Inflected Adjectives. - As already mentioned attributive adjectives take pronominal affixes only if preceded by an inflected determiner. Otherwise they are weakly inflected according to the following pattern:

\begin{tabular}{l|lcc|c|}
\multicolumn{1}{c}{} & Masculine & Neuter & \multicolumn{1}{c}{ Feminine } & \multicolumn{1}{c}{ Plural } \\
\cline { 2 - 5 } Nominative & -e & -e & -e & -en \\
\cline { 2 - 5 } Accusative & -en & -e & -e & -en \\
Dative & -en & -en & -en & -en \\
Genitive & -en & -en & -en & -en \\
\cline { 2 - 4 }
\end{tabular}


The phonological analysis of these affixes is the same as in (12). Their distribution must be governed by particular rules which apply in the environment of [+ Adjective, - Determiner] stems and are given below as (R 10) and (R 11).

We assumed above that adjectives must be recategorized as $[+\mathrm{Adj}$, + Det $]$ in order to be inflected pronominally. This is done by the following rule, which applies to attributive adjectives not preceded by an overtly inflected determiner:

(T 4) Adjective Recategorization

SD: $\mathrm{W}\left[\mathrm{NP}-\mathrm{X}-[+\mathrm{Adj}]-\mathrm{Y}_{\mathrm{NP}}\right] \mathrm{Z}$

$$
\begin{array}{lll}
1 & 3 & 4 \\
\text { where } 2 \neq\left[\begin{array}{l}
+ \text { Det } \\
- \text { Adj }
\end{array}\right][+ \text { Affix }] U
\end{array}
$$

$\mathrm{SC}: 12\left[\begin{array}{c}+ \text { Det } \\ 3\end{array}\right] 4$

With (T 1) through (T 4) the prerequisites for the inffection of determiners and adjectives are in effect completed and we return to the problems of proper inflectional rules.

\section{ORDERED RULES FOR INFLECTION}

6.1. The Principle of Linear Ordering. - The only convention for the operation of (R 1) through (R 8) above was the restriction on repeated application of the same rule to the same stem. Nothing was said, however, about the ordering of rules. The features in (R 1) through (R 8) and even in (IR 1') were specified in such completeness that each given complex symbol can be subject of at least one rule. Therefore it is immaterial in which order one runs through the set of rules. We will now show that a great improvement of the inflectional rules can be achieved if we use the principle of ordered rules and that this improvement accounts for language specific neutralizations and distinctions in morphology in a much more natural way than the use of neutralization rules. That linear ordering of rules is a basic principle in the theory of grammar has been demonstrated by overwhelming evidence. ${ }^{31}$ We therefore make only explicit use of a principle that already pertains to the theory of grammar for many independent reasons.

6.2. Reformulation of the Rules. - We now replace ( $R$ 1) through ( $\mathrm{R}$ ) by the following rules:

(R 1') Dat. Plur.

$[+$ Aff $] \rightarrow n /\left[\begin{array}{c}+ \text { Det } \\ + \text { Plur } \\ + \text { Obl } \\ + \text { Gov }\end{array}\right]$
(R 2') Gen/Dat.Fem./Gen.Plur.

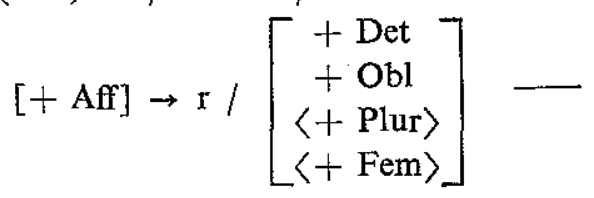

s1 For discussion see, e.g., N. Chomsky, Current Issues in Linguistic Theory (The Hague, 1964). 
(R 3') Nom/Acc.Plur/Fem.

$[+$ Aff $] \rightarrow$ e $/\left[\begin{array}{c}+ \text { Det } \\ \langle+ \text { Plur }\rangle \\ \langle+ \text { Fem }\rangle\end{array}\right]$

(R 5') Gen.Masc/Neut.Adj.

$[+$ Aff $] \rightarrow \mathrm{n} /\left[\begin{array}{l}+ \text { Det } \\ + \text { Adj } \\ + \text { ObI }\end{array}\right]$

(R 7') Acc.Masc.

$$
\begin{aligned}
{[+\mathrm{Aff}] \rightarrow \mathrm{n} / } & {\left[\begin{array}{l}
+ \text { Det } \\
+ \text { Masc } \\
+ \text { Gov }
\end{array}\right] \quad[} \\
& \left(\mathrm{R} 9^{\prime}\right) \text { Nom/Acc.Neut. } \\
& {[+ \text { Aff }] \rightarrow \mathrm{s} / \text { [+ Det }] }
\end{aligned}
$$

(R 4') Dat.Masc/Neut.

$[+$ Aff $] \rightarrow \mathrm{m} /\left[\begin{array}{l}+ \text { Det } \\ + \text { Obl } \\ + \text { Gov }\end{array}\right]$

(R 6') Gen.Masc/Neut.Det.

$[+$ Aff $] \rightarrow \mathrm{s} /\left[\begin{array}{l}+ \text { Det } \\ + \text { Obl }\end{array}\right]$

(R 8') Nom.Masc.

$[+$ Aff $] \rightarrow r /\left[\begin{array}{l}+ \text { Det } \\ + \text { Masc }\end{array}\right]$

We have nine rules now because of (R $\left.5^{\prime}\right)$ which accounts for the /en/-inflection of adjectives in the genitive of masculine and neuter. The other rules again correspond to the eight syncretism fields in (5). This set of rules works now in the following way: first ( $\left.R 1^{\prime}\right)$ is applied, if possible, providing the ending of the dative plural. 'If ( $\left.R 1^{\prime}\right)$ had not applied, then (R 2') must operate in all cases satisfying its feature context. And because of the preceding ( $R 1^{\prime}$ ) there are now no uninflected datives in the plural. Therefore ( $R 2^{\prime}$ ) can provide endings for the two oblique cases only in [ - Plural] environments, whereas in the plural only the [- Governed] genitive is left for /er/. After application of (R 1') and ( $R$ 2') only direct cases are without ending for the plural and the feminine. (R $3^{\prime}$ ) therefore pertains only to nominative and accusative. Since after ( $R$ 3') all plural forms and all feminine cases are inflected, (R 4') through ( $\mathbf{R} 9^{\prime}$ ) can apply only to masculine and neuter singular. Their operation is obvious. It is easy to see that ordering is essential now. (R 7') is the only rule for which another position is possible. It can precede ( $\left.R 6^{\prime}\right)$ and even $\left(R 5^{\prime}\right)$ because it refers to $[+$ Governed] cases which are not affected by (R $\left.5^{\prime}\right)$ and (R 6'). We will make use of this possibility below in order to collapse ( $\left.R 5^{\prime}\right)$ and ( $\left.6^{\prime}\right)$.

After ( $R 9^{\prime}$ ) has operated, only [- Determiner] marked adjectives can have an affix constituent not provided with phonemic content. This will be done now by the weak inflection rules (R 10) and (R 11):

(R 10) Weak Plur./Gen/Dat./Acc. Masc.

$$
\left.[+ \text { Aff }] \rightarrow n /\left\{\begin{array}{l}
+ \text { Adj } \\
+ \text { Plur }
\end{array}\right]\right\}
$$


(R 11) Weak Nom/Acc. Fem/Neut./Nom. Masc.

$$
[+\mathrm{Aff}] \rightarrow \mathrm{e} /[+\mathrm{Adj}]
$$

(R 10), of course, consists of four subrules which must be applied in the given order and which are to be followed by (R 11). Using the principle of double environments we can now concentrate ( $\left.R 1^{\prime}\right)$ through ( $R$ 11) into the following complexes of ordered subrules:

(IR 1) Pronominal Inflection

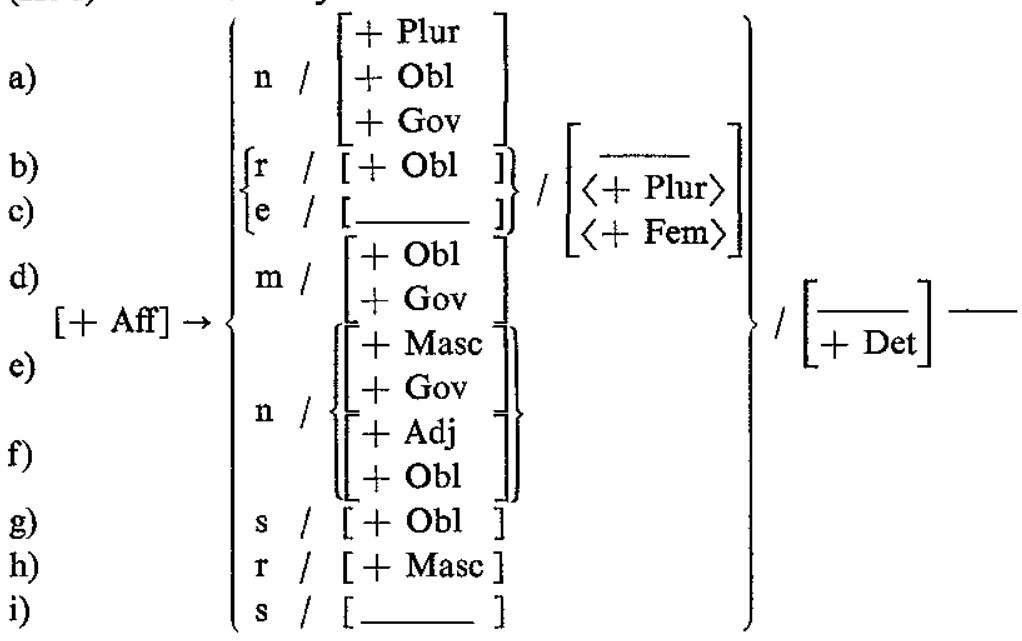

(IR 2) Weak Adjective Inflection

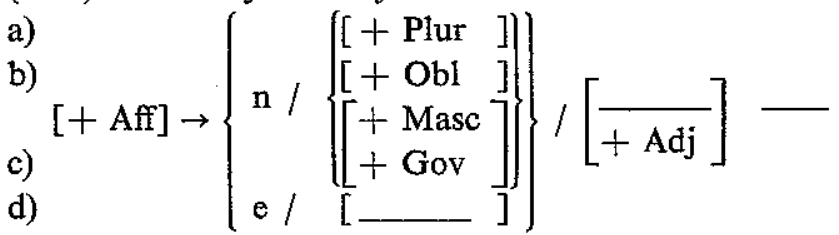

Instead of the 26 syntactic features of (IR 1') (IR 1) requires only 16 features. The cost for the entire weak inflection (IR 2) is 6 syntactic and 2 phonemic features. We will discuss in section 7 the empirical generalization to which this saving of features corresponds.

6.3 The Principle of Disjunctive Ordering. - The convention of non-repeated application governing the former rules has tacitly changed its character in the operation of (IR 1) and (IR 2). Still each subrule may operate only once on a given constituent, but this convention is not yet sufficient now. Since the context is less fully specified, there is in general more then one rule which could operate on a given adjective or determiner. If the prohibition of repeated application concerns only the single rules, then, for instance, each adjective pronominally inflected by (IR 1) would receive subsequently by (IR 2 ) a weak inflection. We must therefore restate the 
convention in question in the following way: Each adjective or determiner must be subject only once to the complex of rules (IR 1a) through (IR 2d). This, however, simply means that these rules are disjunctively ordered; and this again is a basic principle pertaining to the general theory of grammar and motivated by a lot of independent evidence. ${ }^{32}$ It states that if a rule $R$ has been applied then no other rule $R$ ' disjunctive to $R$ can operate on the same item within one cycle. And since for obvious reasons inflectional rules cannot operate cyclically, each adjective and each determiner gets at most one ending. To be more precise: there are according to Chomsky and Halle three basic principles which determine the operation of grammatical rules:

(16) (a) Linear Order

(b) Conjunctive and Disjunctive Order

(c) Cyclic Operation, governed by the syntactic hierarchy

All three principles must be anchored in appropriate notational conditions imposed on the form of possible rules and grammars. To begin with (16) (c), it is connected directly with constituent structure information referred to in the structural description of syntactic and phonological rules. Since in the inflectional rules no reference is made to syntactic information that could reappear several times in the hierarchy of constituents, (16) (c) applies without effect to inflectional rules, and possibly to morphological rules in general. Vacuousness of principle (16) (c) would then be characteristic for the morphological component. If this were true, by the way, rules of the form ( $\mathrm{T}$ 2) through ( $\mathrm{T}$ 4) cannot belong to the morphological rules, since reference to constituent structure is necessary in their structural description.

(16) (a) poses no problem for the notation: it is expressed simply by the overt order of the tules. The situation is most difficult with respect to (16) (b). This principle, developed up till now mainly for phonology, is expressed in the formulation of rules by special use of different types of brackets for disjunctively and conjunctively ordered rules. Since I cannot go into detail here it may suffice to say that I could not find a way to transfer this particular notation to the morphological rules discussed here. Instead of introducing a new notation, I propose the following solution. Let us assume that the morphological component of a grammar may contain two different sets of rules which we may call morphological redundancy rules and morphological rules, ${ }^{33}$ the latter dealing mainly with inflection and similar processes. If we now designate a complex of one or more collapsed rules, e.g. (IR 1), by the term "Rule" and its subrules, e.g. (IR 1a), (IR 1b), etc., by the term "Subrule", then the following principle may be formulated:

32 For details see N. Chomsky and M. Halle, The Sound Pattern of English.

a See fn. 14 and references therein for examples of morphological redundancy rules. These rules are completely different from morphological rules with respect to their function within the grammar. Like syntactic and phonological redundancy rules, they may be considered as belonging to the lexicon. See N. Chomsky, Aspects of the Theory of Syntax, p. 164-70. 
(17) The Subrules of a morphological Rule are disjunctively ordered; the morphological Rules are conjunctively ordered with respect to each other.

This principle makes a very strong claim about the nature of morphological processes, its adequacy is by means obvious and must be justified on empirical grounds. It sounds reasonable to me, however, not only on the basis of the few concrete facts considered here, but also with respect to the character of morphological processes in general. Inflectional and similar affixes are, so to speak, the phonemic realization of particular syntactic features. Language-specific rules state in which way these features are "expressed" by certain affixes, thereby constituting those syncretisms which are characteristic of the morphological pattern of a given language. The assignment of the phonemic shape to a given affix expressing a certain complex of syntactic features is then in a sense parallel to the combination of syntactic and semantic features with their phonological matrix within the lexicon, where disjunction of entries must also obtain. In other words phonemic shape cannot be assigned to the same feature complex more than once. (17) then implies that one rule refers to exactly one set of syntactic and morphological features, the subrules referring to different possible values for these features. Notice that (17) does not imply that there can only be one affix for a given stem. It merely implies that two or more affixes cannot be assigned by disjunctively ordered subrules. Nor does it imply that the same feature, say [Plural], must not appear in several conjunctively ordered rules. Thus in certain noun classes of German there is a special affix for the plural and an additional one for the dative plural, e.g. $/ \mathrm{man}+\mathrm{r}+\mathrm{n}$ /, which finally gives [menern]. The rules for both affixes must refer to [+ Plural] and must be applied conjunctively. But they do not refer to the same complex of features. If that were possible both affixes would have to be introduced by one subrule, which would be a plausible consequence, as can be seen from such cases as Latin dative plural /-bus/, which cannot be split into two affixes. Thus by condition (17) the particular affix structure of a given language is partly reflected in the ordering of morphological rules and subrules.

It should be noted, by the way, that (17) does not exclude repeated derivation as e.g. in analyticity, realizational, etc., since those and similar processes of word formation must be handled by syntactic rules and do not belong to morphology at all. Furthermore, (17) does not exclude repeated application of phonological rules, which may sometimes specify certain consequences of inflectional elements, e.g. on accent.

If it turned out, then, that (17) should be incorporated into the set of general conditions imposed on the form of possible grammars, the notational reflex of principle (16) (b) for morphology would be a collapsing of rules. It remains to be shown whether this is generally possible in a natural way.

As to (IR 1) and (IR 2), these then must be collapsed to a single rule, since application of (IR 2) is not allowed if (IR 1) has already operated. This can be done quite simply with the saving of only one feature. Let $A$ designate the right hand side of (IR 1) and $B$ that of (IR 2). We get then the following complex rule: 
(IR) Inflection of Adjectives and Determiners

$$
[+\mathrm{Aff}] \rightarrow\left\{\begin{array}{l}
A \\
B
\end{array}\right\}
$$

(IR) requires 21 syntactic and 13 phonemic features.

\section{LEXICAL TREATMENT OF INFLECTION}

7.1. Affixes as Lexical Entries. - One could develop somewhat further the analogy between inflection and the function of the lexicon hinted at in the preceding section. Since we have categorized inflections as [+ Affix] by (T $\left.3^{\prime}\right)$, we may treat them as minor categories and let them select their phonemic shape from the minor category lexicon proposed by Fillmore as noted in section 1.2. This requires first a recopying of all features mentioned in (10) as relevant for the inflection of adjectives and determiners onto the constituent affix, because only then the choice from a lexicon containing affixal entries is possible. This duplication could be provided by a transformation following (T 4). Perhaps one could avoid an additional duplication rule by reformulating ( $\mathrm{T} 1$ ) in such a way that the features are not copied on adjectives and determiners but rather on their affixes. This would require ( $T$ 3') to precede (T 1), and ( $\mathrm{T}$ 2) becomes a later deletion rule erasing the previously introduced affixes from ein, kein, mein, etc. under the conditions stated there. We will not decide here, whether such a reformulation, which implies that case, number and gender are not properties of the stems, but of their affixes, is adequate. It obviously raises serious difficulties for certain personal pronouns, where stem suppletion is necessarily dependent on case and number. But it could be used incidentally without difficulty also as the basis for inflection by rules. The feature context in (IR) then becomes a segmental context instead of the sequential one, without a further change being necessary. For the present purpose, however, we will assume that the relevant features can be made part of the affixes without additional complication in the syntactic component.

Under these conditions the inflectional affixes appear as fully developed complex symbols in the final derived Phrase-marker, and the minor category lexicon must contain entries providing the phonemic shape for these complex symbols just as it does for determiners, auxiliaries etc.

7.2. Lexical Markedness for Grammatical Features. - Since now the previously Phrase-marker-inherent features must also appear in lexical entries, it becomes possible to express markedness by $u$ and $m$ in the sense sketched in 2.3.

For the suffix /er/ the minor category lexicon must now contain the following three entries corresponding to the three $e r$-fields in (5) (for greater simplicity we list only the marked features): 
(18)

(a) $\left[\begin{array}{l}m \text { Aff } \\ m \text { Det } \\ m \text { Masc } \\ m \text { cons } \\ m \text { voc }\end{array}\right]$

(b) $\left[\begin{array}{l}m \text { Aff } \\ m \text { Det } \\ m \text { Fem } \\ m \text { Obl } \\ m \text { cons } \\ m \text { voc }\end{array}\right]$

If we use Boolean functions in dictionary entries, ${ }^{34}$ (18) (a) through (c) can be condensed in the following entry:

$$
\left.\left[\begin{array}{l}
m \text { cons } \\
m \text { voc }
\end{array}\right] \text { and } m \text { Aff and } m \text { Det and }[m \text { Masc or }[m \text { Obl and }[m \text { Fem or } m \text { Plur }]]]\right]
$$

By simple logical multiplication (19) yields an alternative of three feature-conjunctions each corresponding to one of the entries (18) (a) - (c). And disjunction of feature complexes is precisely the structure of the dictionary. The following matrix gives the unreduced form for all the considered inflections, again listing only the markings:

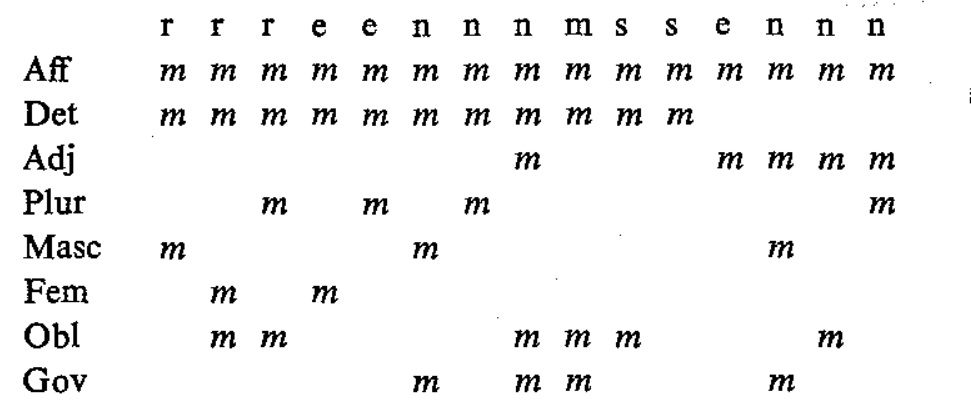

The 50 markings of this representation can be reduced to 32 markings, mainly by eliminating the repeated marking for [Aff], [Det], and [Adj]. Since the phonemic shape of each affix must be given only once, 8 phonemic markings are needed. Thus 40 markings in the lexicon are needed where (IR) requires 34 feature specifications. However, in addition to the sub-lexicon (20) a set of interpretation rules converting the $m$ 's and $u$ 's into ' + ' and ' - ' is required. The lexical entries can be substituted in the appropriate way for affixes in given Phrase-markers only after their operation. These rules would be as follows:

(21) (a)
(a) $[m$ Aff $] \rightarrow[+$ Aff $]$

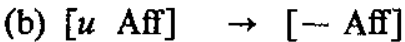
(c) $[m$ Det $] \rightarrow[+$ Det $]$
(d) $[u$ Det $] \rightarrow[-$ Det $]$
(e) $[m$ Adj $] \rightarrow[+$ Adj $]$

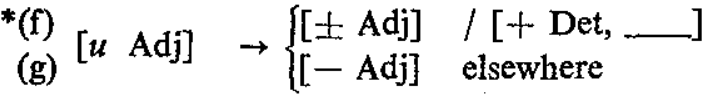

s4 That this is necessary, can be motivated on independent grounds. For details see G. Lakoff, On the Nature of Syntactic Irregularity. 
(h) $[m$ Plur $] \rightarrow[+$ Plur $]$

(i) $\left[\begin{array}{ll}u & \text { Plur }] \rightarrow[- \text { Plur }]\end{array}\right.$

(j) $[m \mathrm{Fem}] \rightarrow[+\mathrm{Fem}]$

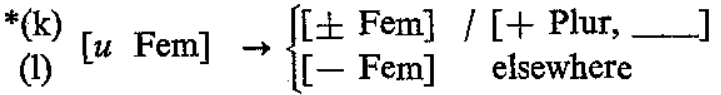

(m) $[m$ Masc $] \rightarrow[+$ Masc $]$

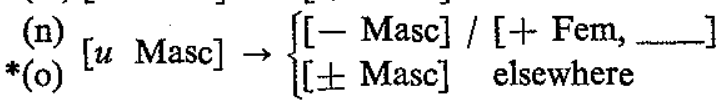

(p) $[m$ Obl $] \rightarrow[+$ Obl $]$

(q) $[u$ Obl $] \rightarrow[-\mathrm{Obl}]$

(r) $[m$ Gov $] \rightarrow[+$ Gov $]$

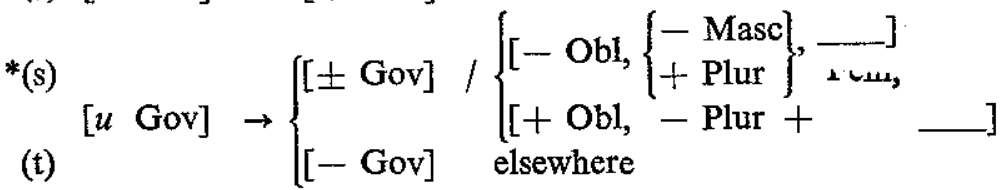

The rules (21) (c) through (o) must be additionally restricted to the environment [+ Affix, __ ], since stems require other interpretation rules. Thus [ $u$ Plur] in nouns may become $[ \pm$ Plur $],[u$ Fem $]$ becomes $[+$ Fem $]$ in female nouns, as noted in section 2.3., etc. ${ }^{35}$ The case features on the other hand are apparently subject to the same interpretation in all environments in German. If applied in the given order, the rules (21) convert the syntactic features of the three entries stated in (18) in the following 12 feature bundles, characterizing exactly the cases of pronominal /r/-inflection:

$\begin{array}{cccccc}\text { Nom-Masc } & \text { Gen-Fem } & \text { Dat-Fem } & \text { Gen-Masc } & \text { Gen-Neut } & \text { Gen-Fem } \\ \text { Sing. } & \text { Sing. } & \text { Sing. } & \text { Plur. } & \text {.... Plur. } & \text { Plur. } \\ \text { Det. Adj. } & \text { Det. Adj. } & \text { Det. Adj. } & \text { Det. Adj. } & \text { Det. Adj. } & \text { Det. Adj. }\end{array}$

\begin{tabular}{|c|c|c|c|c|c|c|c|c|c|c|c|}
\hline Aff & + & & + & + & + & + & + & + & + & + & + \\
\hline Det & + & + & + & + & + & + & + & + & + & + & + \\
\hline Adj & + & - & + & - & + & - & + & - & + & - & $t$ \\
\hline Plur & - & - & - & - & - & - & + & + & + & + & $t$ \\
\hline Masc & + & + & - & - & - & - & + & + & - & - & - \\
\hline Fem & - & - & + & + & + & + & - & - & - & - & + \\
\hline $\mathrm{Obl}$ & - & - & + & + & + & + & + & + & + & + & + \\
\hline Gov & - & - & - & - & + & + & - & - & - & - & \\
\hline
\end{tabular}

At present it is not clear what particular conditions must be imposed on rules like (21), in particular, to what extent they can be made universal conventions, and to

a5 For similar examples of lexical marking with respect to the features [Adj] and [Plur] see G. Lakoff, On the Nature of Syntactic Irregularity. 
what extent they must be part of language-specific grammars. However, at least the starred rules (f), (k), (o), and (s) are idiosyncratic for German, because they are the roots for rather particular syncretisms. Therefore, even if we were to take all other rules as universal, a grammar of German must contain in addition to the lexical markings of (20) the 16 specifications of the starred rules in (21). Note, incidentally, that the rules $(\mathrm{k}),(\mathrm{o})$, and $(\mathrm{s})$ together express essentially the same facts as the neutralization rules (NR 1) through (NR 3). Note furthermore that rules such as (21) imply the refusal of principle (8) of section 3.2.

With respect to the general assumptions on marked syntactic categories put forward by European structuralists, we observe that lexical markedness of inflectional affixes gives no explanation, at least not in a simple way. In the lexicon the plural must always be marked, masculine and feminine gender and the oblique cases mostly but not always, the neuter gender and the direct cases never. These, however, are somewhat vague statements, and it is not clear whether they explain anything.

7.3. Comparison of the Different Descriptions. - The choice between unordered and ordered rules is obvious. The use of ordered rules is to be preferred not only because of the economy in features, but also because the simplification is achieved by means of very general principles governing the form of grammars. There only remains the evaluation of (IR) vs. (20) and (21). If we assume that markings in the dictionary have the same weight as feature specifications in rules, which is by no means a priori obvious, the choice is clearly in favour of (IR): the 34 specifications in (IR) are opposed to 56 of the lexical treatment, if only those rules in (21) are counted which are definitely not universal. But since these totals are not justified with sufficient clarity, further evidence may be adduced. This in turn relies on the principle of ordering. The comparison of ordered and unordered rules has shown quite clearly that ordering is by no means an accidental fact in morphology. The treatment of affixes as lexical entries, however, misses this principle completely. The higher number of feature markings, even within the dictionary, is a direct consequence of this disadvantage. That there is in general no linear ordering within the lexicon corresponds to the basic fact that the choice between different lexical elements compatible with a given Phrase-marker does not depend on language at all, but must be determined by extralinguistic facts. The choice of inflections, on the other hand, is completely dependent on the structure of the given language. Treating inflections as lexical entries would then obscure the deep seated difference between instrinsic and extrinsic properties of language. ${ }^{36}$ On the basis of these considerations (IR) is chosen as the more adequate description of the facts in question.

36 If this consideration is right, it can be made into a rather strong argument against the notion of minor category lexicon. The sample lexicon for determiners and preverbs of English given by Fillmore in "On the Syntax of Preverbs" shows clearly that important simplification can be achieved by restating it as a set of linear and disjunctively ordered rules providing complex symbols with phonemic representations. The notion of dictionary should be reserved, then, for the proper base lexicon, whereas the phonemic shape of minor categories, completely determined by the derived syntactic features, is introduced by ordered morphological rules. 


\section{MARKEDNESS PHENOMENA AND MORPHOLOGICAL, RULES}

8.1. Empirical Purport of Ordered Morphological Rules. - The discussion in the last section shows more clearly what empirical generalization corresponds to the greater simplicity of ordered rules. We may conceive of a disjunctively ordered set of inflectional rules as displaying an inflectional paradigm. The choice among the elements of such a paradigm is fully determined, given a certain syntactic frame, and the ordering of the rules indicates how one has to run through the paradigm in order to make the correct choice using as little syntactic information as possible. Looking at (IR) in this way, we realize that the process starts, roughly speaking, with the most marked category - dative plural - running through the fewer marked cases of plural and feminine down to the most unmarked nominative neuter. However, the correspondence between the order of rules and what one could call degrees of markedness is only a very vague one. And, more important, the order is based only on consideraations of simplicity, no explicit reference to markedness having been necessary. The correspondence between markedness and order is therefore merely ornamental and not an integrated property of the description. We may ask, then, whether such an integration is possible and what could be achieved thereby. This requires some remarks on the motivation of the notion of markedness.

8.2. Markedness in Phonology and Semantics. - The concept of "Merkmalhaftigkeit" was introduced first in phonology, where it means that one element of a correlated pair is more "normal" than the other; more precisely: more conditions are imposed on the articulation of a marked element than on the corresponding unmarked one, given a certain environment. Neutralization then means that one of the conditions is dropped, and the unmarked element shows up. These and similar phenomena are accounted for in Chomsky's and Halle's theory of markedness, where conditions on articulation in this sense appear as lexical markings.

Similar considerations hold for semantic and semantically interpreted syntactic features. Again the marked entity is the less normal one, i.e. more conditions are imposed by it on the discriminations to be made in a given situation. Dropping a condition of this sort corresponds to the appearence of the unmarked entity. Again, conditions on discrimination appear as lexical markings. ${ }^{37}$

It is important to note that Jakobson relied on just these semantic motivations

37 Difficulties arise with semantically interpreted base-rule-inherent features such as [Plural], [Past], etc. With the present conception of the relation between syntax and semantics these elements cannot in general appear as marked in lexical entries. (For exceptions see fn. 11.) However, with respect to interpretation they should obviously be handled in a similar way to such features as [Animate], [Human], etc. We may assume, therefore, that base-rule-inherent features, which have bearing on meaning, are somehow subject to markedness without going into details of this problem. The situation is yet more complicated with respect to case features. Their semantic bearing is strongly advocated by Jakobson, and in my opinion this fact can scarcely be doubted for certain cases. (See fn. 12.) On the other hand, certain case features are purely transformational without any independent meaning. For the time being, I have no ideas for an adequate treatment of this complicated phenomenon. 
when he introduced markedness into morphology. The same holds for Hjelmslev's corresponding notions of extensive and intensive categories.

In phonology as well as in semantics markedness is based on the interpretation of primitive linguistic elements by reference to extralinguistic domains. In so far as these elements and their semantic and phonetic interpretation must be assumed to be universal, the rules for their interpretation as to markedness must likewise be assumed to be universal.

8.3. Markedness in Syntax and Morphology. - One must now deal with the question of the place of markedness with respect to syntactic and morphological features which are only indirect reflexes of semantic properties or have nothing to do with meaning at all. The former type is exemplified by gender features in nouns, the latter by the distinction of strong and weak inflection. For these features the more or less normal, i.e. the marked or unmarked value can be determined neither with respect to semantic nor to articulatory conditions. Since their bearing is only on the internal machinery of the grammar, markedness simply imposes conditions on the application of the given rules. Female nouns, for example, normally undergo the inflectional rules for the feminine gender and need not be marked for [Fem], while non-female nouns require an additional condition if they are to be inflected as feminines. Therefore they must be marked for [Fem]. Similarly, since it is more normal for a noun or verb to be inflected regularly, they do not require markedness for regular inflection, whereas strong verbs must be marked for particular inflection. ${ }^{38}$ Again, lexical markedness expresses additional conditions, though not with respect to semantic or articulatory interpretation, but to the rules to be applied.

So far the discussion of markedness pertains only to lexical features imposing normal or non-normal conditions on articulation, semantic discrimination, and rule application. It may be extended to grammatical, in particular to transformationally introduced features by invoking a further important principle of Chomsky's and Halle's theory of markedness. According to this principle the output of each featurechanging rule undergoes in turn the rules for interpretation of lexical markedness. By this convention each unmarked feature value receives that value which is the unmarked one in the newly created environment. In this way the rules for interpretation of markedness govern the whole grammatical machinery, and as a consequence of this an originally marked or unmarked feature retains this property at each step of the grammatical derivation, unless otherwise stated explicitly in the feature-changing rules. On this basis one might assume the following principle:

(23) For every feature - lexical or grammatical - there are interpretation rules indicating its marked and unmarked value in all possible environments.

By such a principle each feature occurrence would be defined as marked or unmarked.

ss For similar, but much more complicated facts from the domain of syntax see G. Lakoff, On the Nature of Syntactic Irregularity. 
The rules mentioned in (23) must, of course, be motivated by empirical evidence and by their role within the whole grammar. Since we could not consider these aspects in any detail in the present paper, we do not have at our disposal such rules for the relevant features. Notice that the rules (21) depend on the rejected treatment of affixes as lexical entries and therefore cannot serve the required purpose. But even if we were to assume such interpretation rules, they would not influence the inflectional rules, because the latter do not change any of the syntactic or morphological features, but introduce only new phonemic matrices. Therefore only rules for markedness interpretation of phonological features can operate on the output of the inflectional rules in a non-trivial way. But this is not the topic of the present discussion.

8.4. Open Questions. - We return to the question raised at the end of section 8.1., whether the principle of markedness can be integrated into the morphological rules. The foregoing discussion shows that it cannot appear within the rules themselves. Since there are, however, certain widely discussed facts of asymmetry with respect to syncretization and differentiation in inflection which are assumed to be a universal characteristic of human language, ${ }^{39}$ one may look for a general condition imposed on rules of inflection that explains these facts. Given the definition (23) a general condition of the following kind could perhaps be considered:

(24) Infiectional rules or subrules referring to unmarked values cannot precede rules referring to marked values.

This condition would account for the fact that the inflectional rules run through a paradigm from the most marked to the least marked categories displaying asymmetries and syncretisms as noted above. However, though (24) seems to hold for a variety of different inflectional patterns, its soundness will be seen only after the investigation of sufficiently different inflectional systems. More important then the empirical uncertainty of (24) is the following fact: if (24) should be the formal account of an empirical generalization, then it must resultin a measurable simplification of grammars using it over those which do not. For the time being, however, I cannot see how (24) could be reformulated in order to fulfill this requirement. This means then that it cannot be made part of the general theory of grammar.

To be yet more speculative, one could think of another status of principles such as (24). Obviously the historical change within inflectional systems cannot result from pure sound change, i.e. from alteration of the phonological component only. In a dialect of German spoken in Berlin, for example, there has been a merging of dative and accusative with respect to the earlier stage. The result of this merging takes

39 These facts are by no means clear. On the one hand, there is, for example, the principle mentioned in section 4.3. On the other hand, there are important counterinstances. Thus strong feminine nouns in German such as Nacht 'night' show distinction of dative vs. all other cases in the plural (Nächten vs. Nächte), while in the singular all cases are syncretized to Nacht. Jakobson gives several schemes in his "Beitrag zur allgemeinen Kasuslehre", section IX, where distinctions are shown within the series of cases considered as marked, while the unmarked cases are syncretized. 
the form of the dative for the first and second personal pronoun and the form of the accusative in most other paradigms. Clearly it cannot be accounted for by phonological rules. One may ask then, whether there are certain principles governing possible reorganizations of a system of inflectional rules, that is, morphological change. This, perhaps, could be the place for principles such as (24).

8.5. Conclusions. - To come back to earth we may summarize the results of the lengthy discussion of morphological problems as exemplified by German inflection.

1) Inflections are to be introduced by a set of morphological rules intervening between the syntactic and phonological component of the grammar.

2) These rules treat inflectional categories in terms of syntactic features, referring to natural classes of them.

3) The rules are linearly ordered and grouped to complex rules, a complex rule corresponding by and large to an inflectional paradigm. The subrules are disjunctively ordered.

Although illustrated by only one pattern, these principles are intended to govern nominal and verbal inflection not only of German but other languages as well. Later phonological rules must complete the effects of inflectional categories. ${ }^{40}$

DEUTSCHE AKADEMIE DER WISSENSCHAFTEN ARBEITSTELLE STRUKTURELLE GRAMMATIK

40 I am indebted to Morris Halle for reading the manuscript and for suggesting several improvements. All errors, of course, are mine. 